\title{
Thermal Comfort and HVAC Systems Operation Challenges in a Modern Office Building - Case Study
}

\author{
Ema Nemethova ${ }^{1}$, Werner Stutterecker ${ }^{2}$, Thomas Schoberer ${ }^{3}$ \\ ${ }^{1}$ Slovak University of Technology in Bratislava, Faculty of Civil Engineering, Slovakia \\ ${ }^{2}$ Fachhochschule Burgenland GmbH, Pinkafeld, Austria \\ ${ }^{3}$ Forschung Burgenland $\mathrm{GmbH}$, Pinkafeld, Austria \\ e-mail: nemethova.ema@gmail.com
}

\begin{abstract}
The aim of the study is to evaluate the indoor environment conditions in the new-built office building, Energetikum, and consequently suggest the control strategies, which can lead to determination of critical areas and elimination of thermal discomfort. Representative offices have been selected and equipped with portable sensor groups for monitoring of the indoor environment parameters. Contribution is presenting the data obtained from 6 selected rooms during 3 reference weeks - heating, transition and cooling period. The measured results indicate overheating of the rooms, particularly in the ones with the large glazed areas with higher solar gains. The values of indoor air temperature during heating and transition period could not meet the normative criteria according to standard EN 15251:2007 (the cat. II.) during 13\% - $49 \%$ of evaluated time intervals. Consequently, the simulation model of the selected office was created and is pointing to the possibilities of the control system improvement, which can lead to an elimination of the problem with overheating.
\end{abstract}

Key words: indoor environment, thermal comfort, simulation

\section{Introduction}

Environmental comfort in the offices ought to provide optimal conditions for the efficient productivity of the occupants. However, the recent trend in construction, light-weight facades with high portion of glazed components in combination with radiant heating/cooling systems, reveals extensive thermal comfort issues. With regard to the fact, that the lightweight glazed facades are very sensitive to the climatic conditions, properly designed combination of HVAC, lightning and solar shading set-points are crucial for the energy performance, especially in fully glazed buildings or zones. The research is focused on environmental behaviour of new-build office building, particularly on the problem with thermal discomfort.

\section{New-type office building - building with large glazed areas}

The recent trend of transparent buildings with a high portio of glazed areas is usually initiated by architects in order to provide more daylight and better view for the users. The glass parts 
of the façade are installed not only to serve as physical and visual connection between indoor and outdoor environment, but also for the aesthetical sense.

\subsection{Thermal comfort issues in the spaces with large glazed areas}

The results obtained from many actual investigations indicate that the buildings (mainly with administrative purpose) with the light-weight glazed facades are having significant problems with thermal comfort. Big glazed areas are always related to higher energy losses during the heating season and overheating of indoor spaces because of the direct sun [1]. Moreover, it is claimed that the energy demands for different highly glazed buildings may vary more than for buildings with traditional facades since the glazed alternatives are particularly sensitive to the outdoor conditions [2].

During the summer are the problems with the interior overheating more or less expected. However, the cold days with high amount of the solar irradiation, when the solar gains exceed the energy demands for the heating, are the crucial area of the HVAC design. This problem is very important in buildings with a centralized heating and ventilation system where some parts of the buildings should be heated and some cooled at the same time. The worst thermal conditions are in these parts of the building, which are under the influence of the direct sun. To maintain the indoor environment at the level of comfort, the operation of automatically controlled shading elements is also unavoidable. However, to protect the building from unwanted solar gains, the compromise between the natural light and solar gains has to be done.

\subsection{Impact of the overheating on the occupants}

The researches on people's performance while working under different thermal conditions showed the results indicating lower performance during the uncomfortable air temperature period [3]. According to Niemmela et al. people performance decreased by $2.2 \%$ by every 1 ${ }^{\circ} \mathrm{C}$ over $25^{\circ} \mathrm{C}$ [4]. Another research in an office building showed performance decrease by 15 $\%$ when the temperature increased from $24.8{ }^{\circ} \mathrm{C}$ to $26^{\circ} \mathrm{C}$ [5].

\subsection{The radiant heating/cooling systems implementation}

As there is an obvious and indisputable need for an increase in the efficiency of energy utilisation in buildings and in the energy supply system, low-exergy systems are being increasingly implemented in the building technology. Radiant heating systems are very suitable for combination with renewable energy sources, e.g. heat pumps and solar collectors. The outside weather conditions, solar irradiance, changes in internal heat gains and small heat accumulation capability of the light-weight facade can result in relatively dynamic changes in thermal balance of the building. Due to the high time constant, i.e. slow reaction of the radiant heating/cooling, the system may not be able to respond to these changes fast enough to assure a comfortable thermal environment, which can lead in naturally ventilated buildings to temperatures as high as $29.5^{\circ} \mathrm{C}$ [6]. It is an essential task to learn, how to control this type of currently popular buildings, where light-envelopes with the combination of radiant heating/cooling systems are implemented, as the risk of the overheating during is grows with increasing solar radiation rates. 


\section{Description of the reference object}

Due to the lack of currently constructed suitable experimental buildings, in most cases, isolated individual technology tests are being provided, taking place only under laboratory conditions or simulation environment. Therefore, an interdisciplinary living laboratory, the Energetikum, was designed. It allows influence of the real user behaviour on the development of alternative energy supply systems, storage technologies and control engineering strategies in scale 1:1. The investigation of the indoor environment, as a result of properly designed control of HVAC systems and other building technology, was one of the main purpose of the project. The Energetikum is used as an office building for employees of Research Burgenland GmbH since April 2015.

\subsection{Building envelope, construction and thermal properties}

The two-storied building, located in Pinkafeld, Burgenland (Austria), has two types of the façade to eliminate the risks of higher heating demands during the winter and provide the best conditions for the natural light infiltration. Opaque surfaces create 82 percent of the envelope and the light-weight components or windows 18 percent of the envelope. The light-weight (post and beam) façade is implemented in the parts of the building envelope orientated to the West-South-West and South-South-East, where the thermal gains during the heating period can lower the energy demand of the spaces. The external blinds prevent the indoor air during the periods with high solar radiance from overheating. North-North-West and east-north-east facades are designed as reinforced concrete walls with $160 \mathrm{~mm}$ of thermal insulation. All the transparent parts of the façade (windows, post and beam façade, entrance portal) have a triple glazing. The thermal transmittance value of the individual components varies between 0.79 and $1.10 \mathrm{~W} /\left(\mathrm{m}^{2} . \mathrm{K}\right)$ in accordance to the ratio of glazed area to total surface area.

\subsection{Description of installed HVAC systems}

A brine/water heat pump was installed to supply the object with the heat. Heat pump deprives the primary energy from energy baskets and helix probes (located around the building) and a surface collector under the fundamentals of the building. The available area for geothermal energy is too low to cover the power supply created by heat pump. Therefore, an additional energy source, gas boiler, was installed.

Three separated distribution systems are implemented to the heating/cooling system:

- $\quad$ Underfloor heating system (wet-laid);

- Thermally active building core (in the middle of the concrete ceiling);

- Near-surface thermally active building core (on the surface of the concrete ceiling).

Systems can run simultaneously or separated, depending on the current demands. A separate control loop of the 3 systems of the upper floor was installed in order to the request on independent operation of the systems. The heating/cooling is operating on the same temperature difference between inlet and outlet to avoid the hydraulic problems.

Energetikum is mechanically ventilated and provides the complex air-conditioning. Air exchange is fully covered by mechanical ventilation, the window-openings are not essential to maintain the minimal air change rates. The air distribution system is performed by ventilation 
pipeline to dedicated air zones, where each room is considered as a separate zone. Variable volume flow controllers adjust the desired amount of the air. They are located in the assigned rooms. Inlet and outlet of the air is provided through the duct grills in the spiro piping.

\section{Indoor environment assessment and determination of the critical areas}

For monitoring of the various indoor environment indicators such as air temperature, relative humidity, carbon dioxide concentration, and portable measuring sensor groups were installed in selected offices in 2016. Furthermore, the energy consumption sensors, sensors measuring heating and ventilation systems properties and the weather station measuring ambient conditions have been installed simultaneously. Based on the recorded data, it is possible to evaluate the indoor environment quality, energy consumption and behaviour of the HVAC systems.

In summary, three monitoring groups aimed at different aspects of the building, have been already installed:

- $\quad$ Energy consumption and HVAC system sensors - in engine room measuring temperatures and flow rates;

- Portable sensor groups - in corresponding offices - measuring indoor air temperature, humidity and $\mathrm{CO}_{2}$ concentration;

- $\quad$ Sensors monitoring ambient conditions - on the roof of the object - measuring air temperature and humidity.

\subsection{Indoor environment monitoring and installed technology}

Beside the pre-installed SIEMENS sensors, which are aimed at the HVAC operation and control, the portable "monitoring trees", with highly sensible sensors were installed. These are helping to detect the problems with indoor environment and energy consumption. There is a potential of energy-saving improvements via applications of different control strategies to the system.
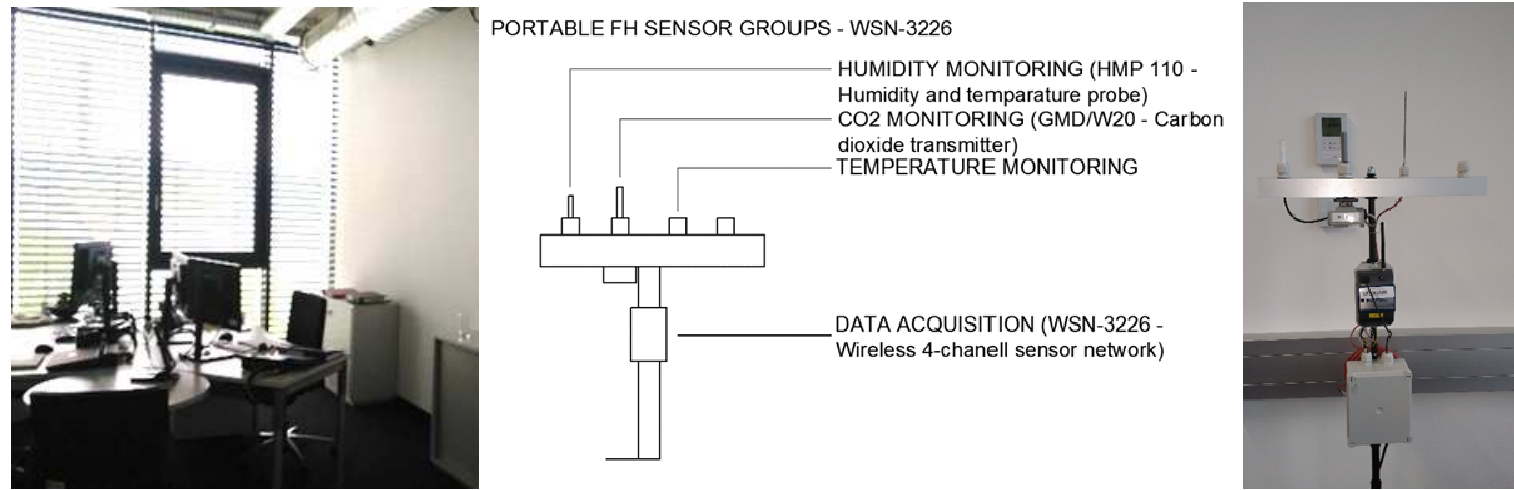

Figure 1: Installed portable monitoring technology - SIMULATION ROOM 1/1 
Table 1: Parameters of portable measuring group in a reference room

\begin{tabular}{|c|c|c|c|}
\hline $\begin{array}{c}\text { Sensor } \\
\text { type }\end{array}$ & $\begin{array}{c}\text { Measured } \\
\text { parameter }\end{array}$ & Mode & Location \\
\hline T_I 1.1 & Temperature & in use & \\
\hline rF 4.2 & Humidity & in use & $\begin{array}{c}\text { Simulation Room } \\
1 / 1\end{array}$ \\
\hline CO2 5.1 & Carbon dioxide & in use & \\
\hline S 3.1 & Air velocity & not in use & \\
\hline
\end{tabular}

\subsection{Results and observations}

The time samples were collected during three reference weeks in year (2016) and the data was sorted out ac-cording to the working hours (6:00 AM - 6:00 PM) and assessed in accordance with EN 15251:2007.

\subsubsection{Thermal comfort}

According to EN 15251, the room can be classified into one of the four categories of the indoor environment. The nominal level of expectations for new and renovated buildings is represented by category II $\left(20-24{ }^{\circ} \mathrm{C}\right.$ for heating, $23-26{ }^{\circ} \mathrm{C}$ for cooling).

Results of the air temperature and classification into the four categories of thermal comfort (I to IV) are shown in Figure 2. Category IV can be accepted for only a very limited time period. The results indicate that the desired thermal environment was achieved for only a limited period of time, mostly caused by excessive air temperature.

According to Figure 2, thermal environment in the building suffers on the thermal dis-comfort during all three periods. The overheating mainly occurs in the transition and heating period, during heating periods, the discomfort is mainly caused by temperatures inferior to the values required in standard EN 15251.

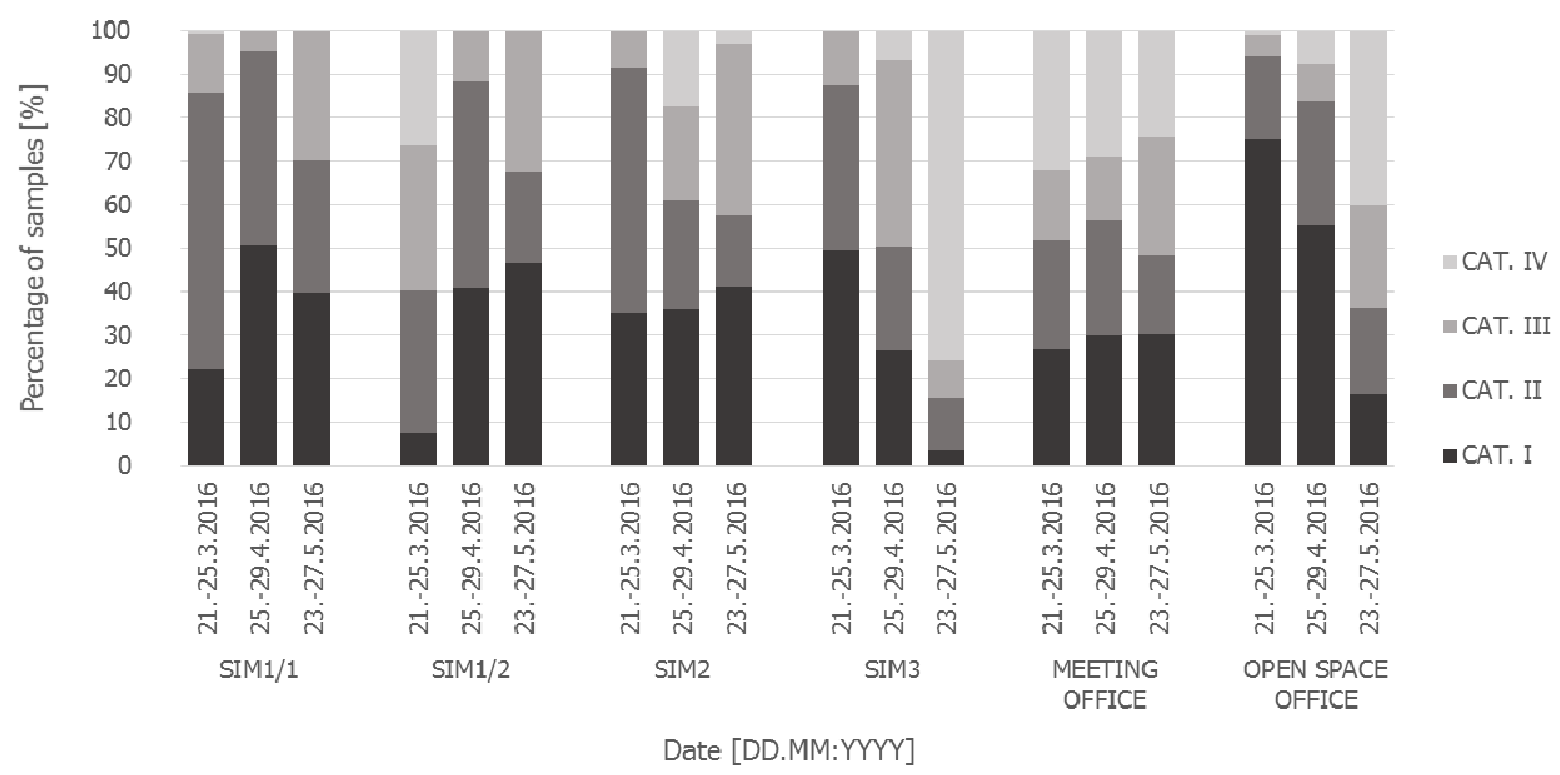

Figure 2: Classification of thermal environment into 4 cat. in accordance with EN 15251 


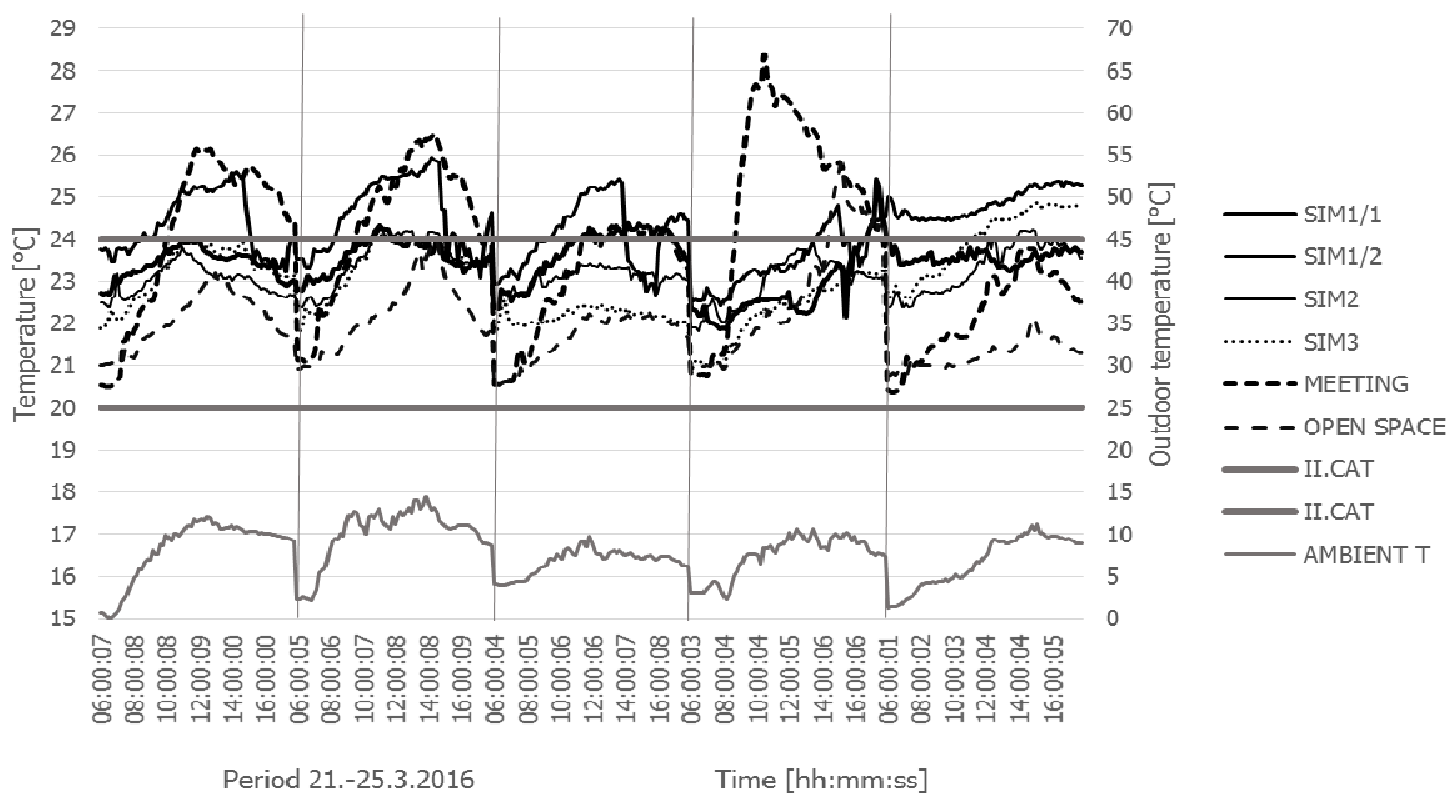

Figure 3: Comparison of indoor air temperatures in the reference offices during the occupied time intervals of evaluated heating period

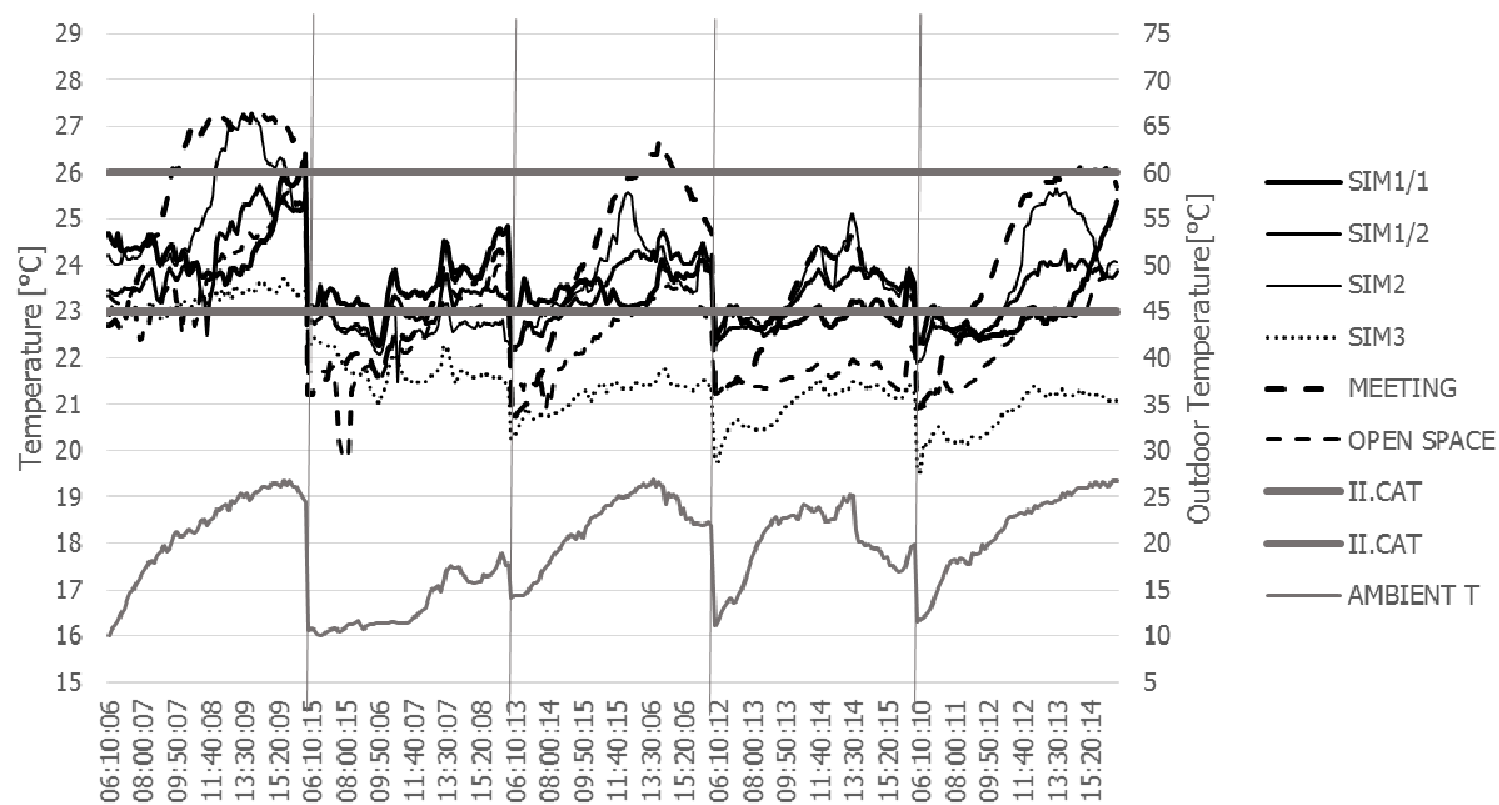

Period 23.-27.5.2016 Time [hh:mm:ss]

Figure 4: Comparison of indoor air temperatures in the reference offices during the occupied time intervals of evaluated cooling period

The temperature curves in Figure 3 and Figure 4 are presenting the amplitudes of indoor air temperature in the reference offices. Generally, the temperature range is above the desired 
value during the heating period and below the desired area during the cooling period, which suggests that the control system is not considering the adaptive principle. By adjusting of the set temperatures or control settings (e.g. PI controller, shading devices, flow rates) it would be possible to save significant amount of the energy simultaneously with thermal comfort enhancement.

Table 2 presents, how many samples fulfil the criteria on thermal comfort according to the standards. In result, none of the assessed offices meets the criteria on thermal environment, as more than $90 \%$ of evaluated samples exceed the limits for cat. II. (EN 15251).

Table 2: Description of the reference offices and summary of thermal comfort assessment

\begin{tabular}{|c|c|c|c|c|c|c|c|}
\hline \multicolumn{4}{|c|}{ Description of the reference offices } & \multicolumn{4}{|c|}{ I-II. CAT - EN 15251} \\
\hline $\begin{array}{c}\text { Office } \\
\text { identification }\end{array}$ & $\begin{array}{l}\text { Orientation } \\
\text { (exterior } \\
\text { walls) }\end{array}$ & $\begin{array}{c}\text { Number } \\
\text { (exterior } \\
\text { walls) }\end{array}$ & $\begin{array}{c}\text { Glass / } \\
\text { Wall }\end{array}$ & $\begin{array}{c}21.3 .- \\
25.3 .201 \\
6\end{array}$ & $\begin{array}{c}25.4 .- \\
29.4 .201 \\
6\end{array}$ & $\begin{array}{c}23.5 .- \\
26.5 .201 \\
6\end{array}$ & Sum. \\
\hline & {$[-]$} & {$[-]$} & {$[\%]$} & {$[\%]$} & [\%] & [\%] & {$[\%]$} \\
\hline SIM1/1 & $\mathrm{W}$ & 1 & 100,00 & 85,53 & 95,39 & 70,24 & 83,72 \\
\hline SIM1/2 & \begin{tabular}{l|l}
$\mathrm{S} /$ & $\mathrm{W}$ \\
\end{tabular} & 2 & 100,00 & 40,08 & 88,47 & 67,76 & 65,44 \\
\hline SIM2 & $\mathrm{S}$ & 1 & 100,00 & 91,50 & 61,08 & 57,39 & 69,99 \\
\hline SIM3 & $\mathrm{S} / \mathrm{E}$ & 2 & 66,35 & 87,44 & 50,42 & 15,52 & 51,13 \\
\hline MEETING & \begin{tabular}{l|l}
$\mathrm{S} /$ & $\mathrm{W}$ \\
\end{tabular} & 2 & 100,00 & 51,56 & 56,58 & 48,30 & 52,15 \\
\hline OPEN_SPACE & $\mathrm{W} / \mathrm{N}$ & 2 & 61,32 & 94,06 & 83,75 & 36,06 & 71,29 \\
\hline
\end{tabular}

The peak of the overheating occurs during the afternoon, as a consequence of the solar gain accumulation and low heat losses. The areas with south/west orientation with higher solar radiation rates are more sensitive to overheating than eastern parts. The amount of external walls and consequently higher portio of glazed components significantly influences the sensitivity to the solar radiation and the heat losses. However, as the automatic shading system was not in the operation during the evaluated time periods, the behaviour of occupants strongly influenced the thermal conditions in the corresponding offices.

Regarding to the fact, that the building is still in the trial operation and the elimination of the existing problems was one of the main research tasks, the indoor is being observed to find the most suitable solutions for the improvement of critical areas of the comfort. The feasible tool is the adjustment of control system, particularly putting the automatic shading devices to the service. Consequently, the different control strategies of HVAC systems should be considered, which creates the challenge for the further study and research.

\subsubsection{Indoor air humidity and quality}

The relative air humidity was satisfactory (I. cat) among more than $95 \%$ of the time samples from the heating and transition period. As the adiabatic cooling is installed in the air conditioning unit, higher values of relative humidity can occur during the days with higher ambient temperature and cooling demand. The indoor air humidity classification according to 
EN 15251 in 6 reference offices during the cooling period is displayed in the Figure 5. Through that, the indoor air humidity is in this case, comparing to the indoor air over-heating, less important issue, the higher relative humidity values can cause health problems.

The $\mathrm{CO}_{2}$ concentration outside was not measured during the whole reference period. In the evaluation, the $\mathrm{CO}_{2}$ concentration outdoors was considered at the value $380 \mathrm{ppm}$ which was the average value of short-term measurement. The indoor air quality in all reference areas during all three periods met the criteria on the air quality required by standard EN 15251 (350 ppm above the concentration outside - Cat. I.), which results from properly designed and operated ventilation system.

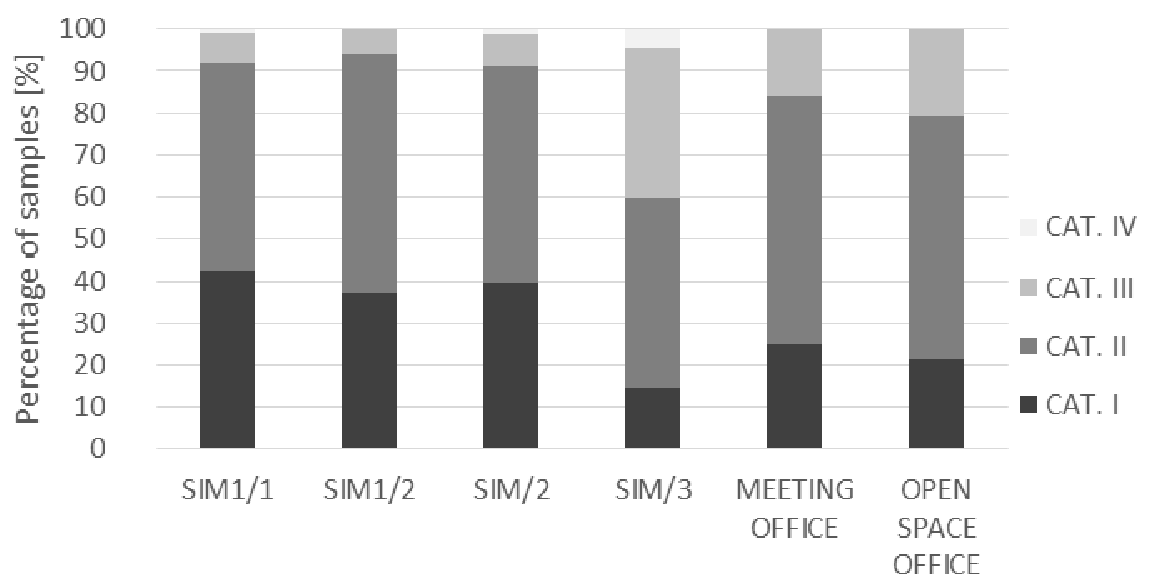

Time period 23.-27.5.2016

Figure 5: Classification of the reference rooms during the cooling period according to relative indoor air humidity into 4 categories

\section{Simulation of the reference room with regard to the impact of the control on the thermal environment}

As a tool to examine the possibility of overheating reduction, the simulation of reference room located in the object was provided. Simulation room 1/1 was selected, as the orientation and portio of glazed areas were convenient for the experiment. As the problem with the thermal comfort during the cooling period (temperatures lower than required by standards) caused by low set-point temperatures of the cooling system, can be quite easily reduced, the reference week from the heating period was chosen for the study. The presented model was developed within TRNSYS environment.

\subsection{HVAC systems and control}

The system of radiant floor heating with stabile flow rate $-320 \mathrm{~m}^{3} / \mathrm{h}$ was implemented to the model to cover the heat demand of the zone. Inlet temperature is maintained at the desired value by three-way mixing valve. Figure 6. Presents the floor plan of Simulation room 1/1 with implemented floor heating circuits. 


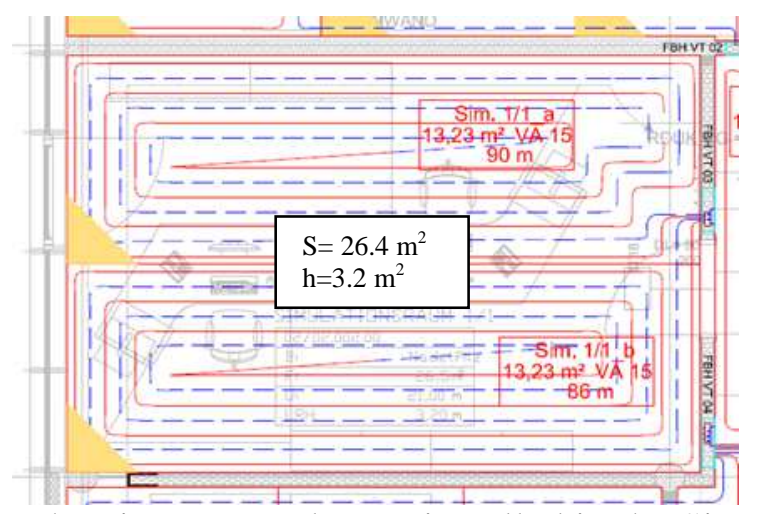

Figure 6: The floor heating system layout installed in the Simulation room 1/1

A PI controlling algorithm was applied to minimize the temperature fluctuations at around 21 ${ }^{\circ} \mathrm{C}$ during the occupied time periods and $16{ }^{\circ} \mathrm{C}$ during the night by adjusting the inlet flow rate temperature of the radiant heating.

The PI control algorithm is based on the following equation with two con (1):

where $\mathrm{u}(\mathrm{t})$ is the manipulated value; $\mathrm{K}_{\mathrm{p}}$ is the proportional gain and $\mathrm{K}_{\mathrm{i}}$ is the integral gain; and $\mathrm{e}(\mathrm{t})$ is the error between the set-point value and the process value. The controller was set according to the Cohen-Coon tuning rules.

The normative air change $4[1 / \mathrm{h}]$ is provided by ventilation system. The inlet air temperature varies and ranges between $17{ }^{\circ} \mathrm{C}$ and $21{ }^{\circ} \mathrm{C}$. The air change rate is controlled by three stage controller depending on the $\mathrm{CO}_{2}$ concentration of the indoor air. The temperature of inlet is controlled proportionally, depending on the amount of the solar radiation.

The shading system with $80 \%$ impenetrability is protecting the room from the redundant solar gains. The occupation, lightning system and installed equipment are also integrated to the model.

\subsection{Application of the control system set-point variations}

Four set-point variations (Table 3) were selected to examine the influence of shading and ventilation system on the thermal comfort. The position of blinds was assigned according to the amount of incident solar radiation to the external wall. The excessing of the solar radiation value $600 \mathrm{~kJ} / \mathrm{h} \cdot \mathrm{m}^{2}$ causes that the shading system fully covers the window, which results to reflection of $80 \%$ of the solar radiation. Otherwise, the shading is covering $30 \%$ of the window area. The ventilation system is set to the temperature $21{ }^{\circ} \mathrm{C}$. However, when the shading system is not capable to cover the solar radiation, the temperature can be proportionally lowered to $17{ }^{\circ} \mathrm{C}$. During the night, the temperatures and air change rates are decreasing, according to the night setback. 
Table 3: Set-point comparison - 4 Variations (V1 - V4)

\begin{tabular}{|l|c|c|c|c|}
\hline & Variation 1 & Variation 2 & Variation 3 & Variation 4 \\
\hline Shading system operation & $\begin{array}{c}\text { On } \\
(30 / 100 \%)\end{array}$ & Off & $\begin{array}{c}\text { On } \\
(30 / 100 \%)\end{array}$ & Off \\
\hline Ventilation inlet temperatures & $17-21^{\circ} \mathrm{C}$ & $17-21^{\circ} \mathrm{C}$ & $21^{\circ} \mathrm{C}$ & $21^{\circ} \mathrm{C}$ \\
\hline
\end{tabular}

\subsection{Simulation results and observations}

The indoor air temperatures with corresponding solar radiation values during the cooling period are presented in Figure 7.

Obtained results are indicating the importance of the automatic and properly designed control of the shading system. Even during the days, when the air temperature does not exceed $10{ }^{\circ} \mathrm{C}$, the solar gains are significantly influencing indoor environment. The temperatures in variation 2 and 4 are getting up to $26^{\circ} \mathrm{C}$, which causes the thermal discomfort. This can be easily eliminated by putting the shading devices to the operation.

In spite of the fact, that the inlet ventilation temperature seems to influence the indoor air temperature slightly, the positive effect during the peak gains should not remain unneglectable. For more detailed results, the further analysis should be provided.

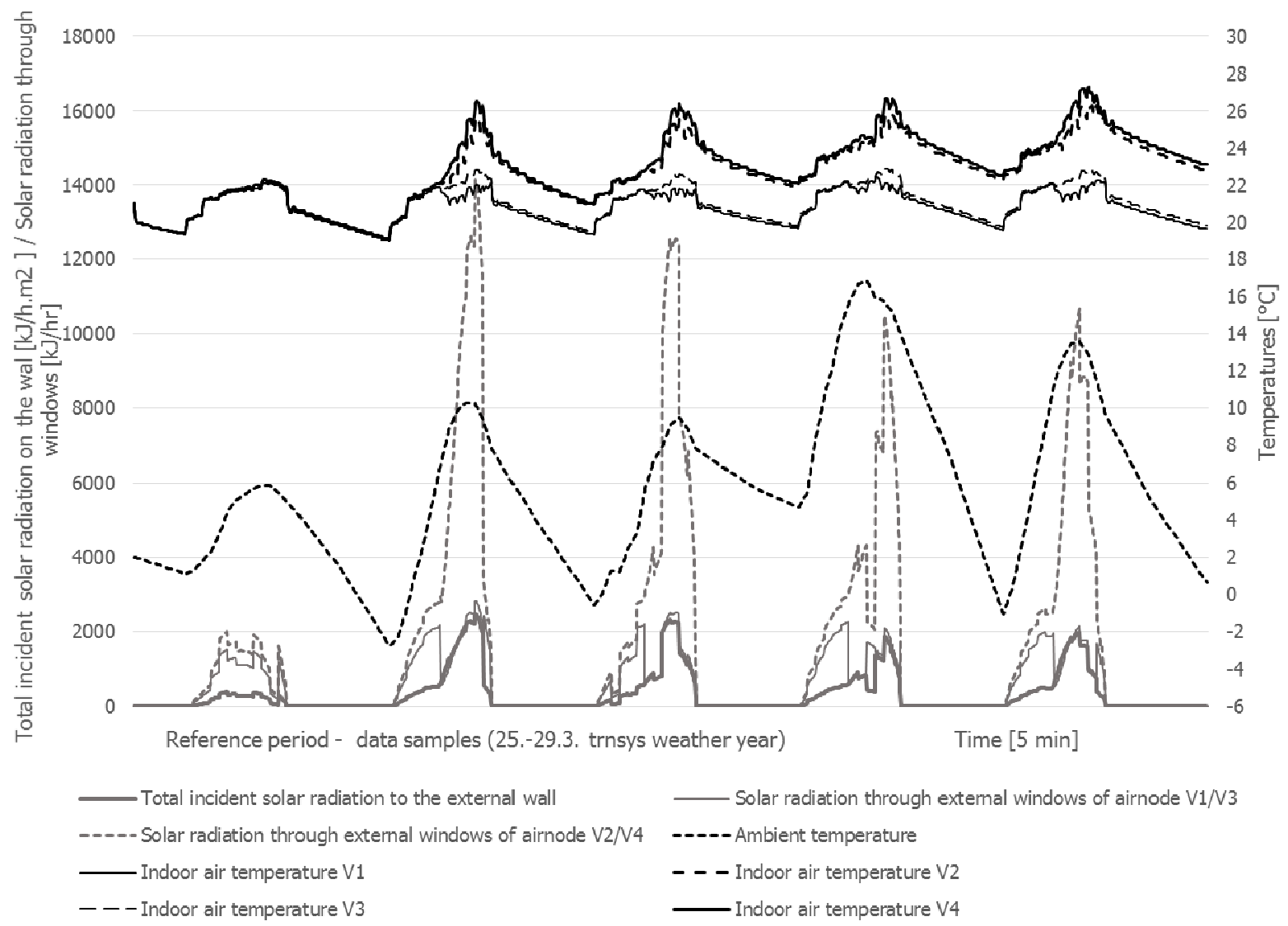

Figure 7: Simulation results - air temperatures and solar radiation profiles - 4 Variations 
The correlation between the indoor air temperature and solar radiation passing through the external wall is presented in Figure 8. Considerable difference between the optimally designed Variation 1 and improperly controlled Variation 4 can be observed. The trend line is not only more moderate and shorter (according to lower radiation and temperature values), which indicates better response to the radiation.
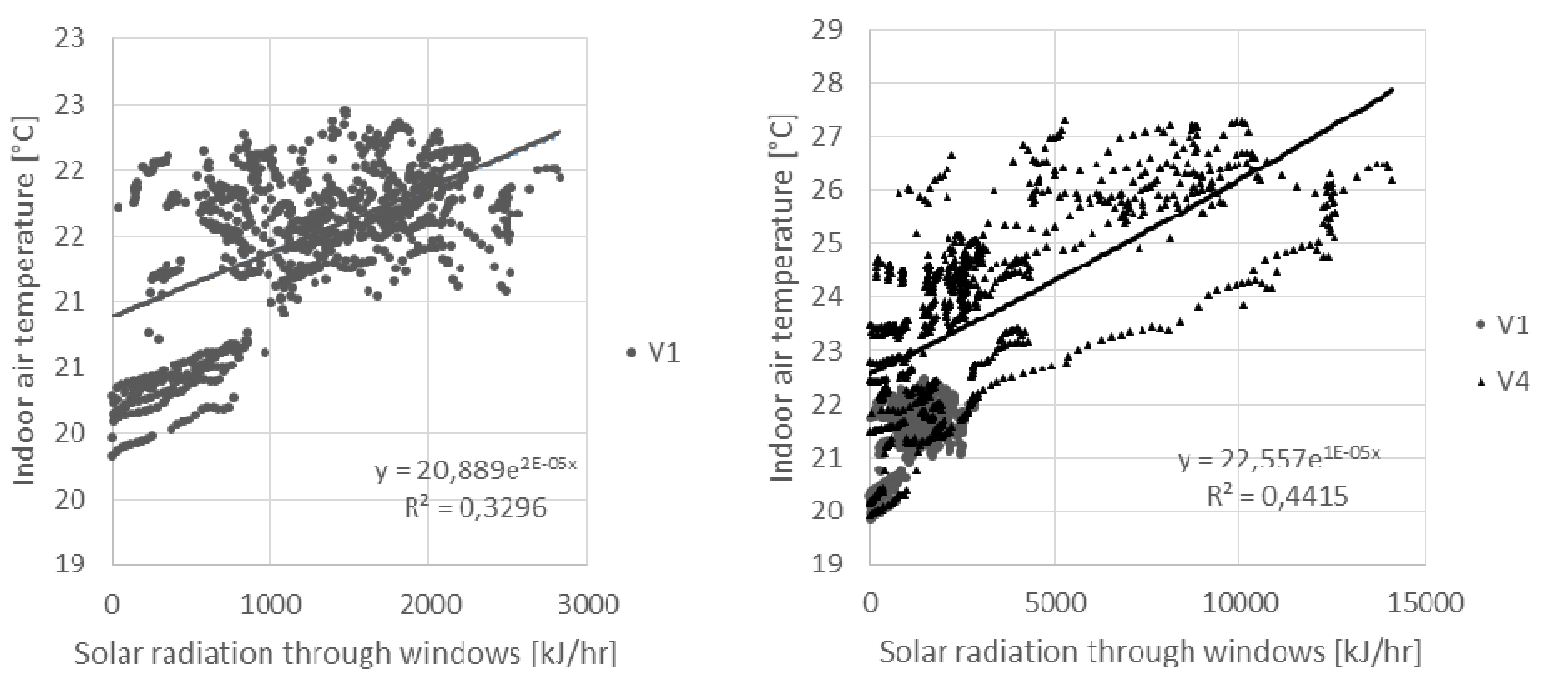

Figure $8 \mathrm{a}$, b: The correlations between solar radiation and indoor air temperature with exponential trend lines; a) Variation1 (left), b) Variation 4 (implemented version 1) (right)

\section{Discussion}

During the first simulated day, with low level of the solar radiation, the response of all 4 variations is very similar. However, the consecutive days with higher solar radiation are rapidly changing the indoor air temperature values. The temperature difference between Variation 1 and Variation 4 is reaching over $5^{\circ} \mathrm{C}$. According to the real experiments, during the overcast days, the indoor air temperatures ranges were approximately at the same level in both cases, using fully closed and fully opened venetian blinds. On the other hand, during the sunny days, the air temperatures differed for $2^{\circ} \mathrm{C}$ [7]. The difference would be higher, if more effective external shading devices would have been used instead of the venetian blinds.

The calculated value $600 \mathrm{~kJ} / \mathrm{h} \cdot \mathrm{m}^{2}$, used as a set-point for the closing of the blinding, is very similar to $189 \mathrm{~W} / \mathrm{m}^{2}$ (equals to $678 \mathrm{~kJ} / \mathrm{h} \cdot \mathrm{m}^{2}$ ), which was the set point suggested by Wankanapon and Mistrick [8]. In the study it was able to save about 13-16 \% of cooling energy in the buildings located in USA.

\section{Conclusion}

As the manual shading was turned on during the measured real reference period, the real temperatures were slightly lower, than the simulated outputs in the variation 4. However, in both cases is the behaviour of thermal environment very similar. The application of adequate 
control setting can possibly result in thermal comfort enhancement and apparent reduction of the overheating. By the lowering of heater (heat exchanger) power output in the installed air conditioning unit, the cost-saving reduction of the inlet temperature of the ventilation system can be achieved, which will consequently lead to the thermal discomfort reduction.

\section{Acknowledgement}

The authors want to thank all supporters, the project energy4buildings is funded by the Austrian Ministry for Transport, Innovation and Technology BMVIT and the Austrian Ministry of Economy, Family and Youth BMWFJ within the funding scheme COIN.

\section{Literature}

[1] Brunner, C., Baumgartner, T., Bruhwiler, D., Schneiter, T.F. \& Steineman, U. (2001). Highly Glazed Buildings - Comfort and Energy Efficiency, SIA (Swiss Society for Engineers and Architects), D 0176, Switzerland.

[2] Carmody, J., Selkowitz, S., Lee, E., Arasteh, D. \& Willmert, T. (2004). Window Systems for High-Performance Buildings. New York: W.W. Norton \& Company, 400.

[3] Šeduikyte, L. \& Paukštys, V. (2008). Evaluation of indoor environment conditions in offices located in buildings with large glazed areas. In: Journal of Civil Engineering and Management, $14: 1,39-44$.

[4] Niemela, R., Hannula, M., Rautio, S., Reijuka, K. \& Railio, J. (2002). The effect of indoor air temperature on labour productivity in call centres - a case study. In: Energy and Buildings 34, 759-764.

[5] Federspiel, C., Liu, G. \& Lahiff, M. (2002). Worker performance and ventilation: analyses of individual data for call-centre workers. IN: Proc. of Indoor Air 2002, 9th International Conference on Indoor Air Quality and Climate. Monterey, CA, USA, 796-801.

[6] Nemethova, E., Petras, D. \& Krajcik, M. (2016). Indoor environment in a high-rise building with lightweight envelope and thermally active ceiling. In: CLIMA 2016: Proceedings of the 12th REHVA World Congress. Aalborg, Denmark, 22.-25.5.2016. Aalborg: Aalborg University, 2016, online.

[7] Tzempelikos, A., Bessoudo, M., Athienitis, A. \& Zmeureanu, R. (2007). The impact of shading on thermal comfort conditions in perimeter zones with glass facades. Retrieved July 17, 2016, from http://www.inive.org/members_area/medias/pdf/Inive\%5CPalencAIVC2007\%5CVolume 2\%5CPalencAIVC2007_V2_096.pdf

[8] Wankanapon, P. \& Mistrick, R. G. (2011). Roller Shades and Automatic Lighting Control with Solar Radiation Control Strategies. Retrieved September 21, 2016, from http://www.builtjournal.org/built_issue_1/03_pimonmart.pdf

[9] European Committee for Standardization (2008). EN 15251: Indoor environmental input parameters for design and assessment of energy performance of buildings addressing indoor air quality, thermal environment, lighting and acoustics. Brussels. 